\title{
Vegetation dynamics during different abandoned year spans in the land of the Loess Plateau of China
}

\author{
Jian Hou • Bojie Fu
}

Received: 29 March 2013 / Accepted: 14 September 2013 / Published online: 24 September 2013

(C) Springer Science+Business Media Dordrecht 2013

\begin{abstract}
In this semi-arid area, many studies focused on the two-phase vegetation pattern were carried out to explore a changing vegetation trajectory on degraded land. However, this study conducted an analysis of a two-phase vegetation pattern and explored the successional vegetation trajectories in a positive succession without disturbance. In this work, 60 randomly distributed plots $(1 \times 1 \mathrm{~m})$ were invested on four abandoned land areas (4-, 12-, 22-, and 50-year abandoned land) to determine attributes of vegetation, and soil physical and nutritional properties. It was found that vegetation distribution development went from homogeneous on 4-year abandoned land to heterogeneous on 50-year abandoned land, with a positive succession. Meanwhile, there was a significant difference in soil physical and nutritional properties for the inside and outside of vegetation patches. Vegetation patches can supply better soil physical and nutritional properties for vegetation than bare patches along the abandoned time. Vegetation diversity changes without a regular trend which may be due to the effect of environment and interspecies competition. This work picked up the slack for vegetation patterns succession research and provided a quantitative analysis approach.
\end{abstract}

Keywords Vegetation pattern - Vegetation diversity · Vegetation cover $\cdot$ Succession · Loess Plateau

\footnotetext{
J. Hou • B. Fu $(\bowtie)$

State Key Laboratory of Urban and Regional Ecology, Research Center for Eco-Environmental Sciences, Chinese Academy of Sciences,

P. O. Box 2871, Beijing 100085, People's Republic of China e-mail: bfu@rcees.ac.cn
}

\section{Introduction}

Recently, there has been growing concern about the development of vegetation patterns (Imeson and Prinsen 2004; Boer and Puigdefabregas 2005; Puigdefabregas 2005; Saco et al. 2007; Mayor et al. 2008; Pellerin et al. 2009; Yetemen et al. 2010) and diversity (Buhk et al. 2007; Kitazawa and Ohsawa 2002; Firbank et al. 2003a; Haines-Young et al. 2003; Pearman and Weber 2007; Ellum et al. 2010; Martin et al. 2010; Randriamalala et al. 2012; Rickert et al. 2012) in natural succession, in order to reveal the relationship between vegetation and the environment in depth. So, many studies of successional processes on set-aside (Firbank et al. 2003b; Critchley and Fowbert 2000) and former arable land (Walker et al. 2004; Donath et al. 2007) have been carried out. In a semi-arid area, though many studies have explored the ecological consequences of land abandonment on vegetation dynamics, successional trajectories are still little understood (Bonet 2004). Meanwhile, though a positive effect of land abandonment on vegetation diversity has been found by several studies (Dana and Mota 2006; Donath et al. 2007), a negative affect was also found by some (Rickert et al. 2012; Jacquemyn et al. 2011). In terms of vegetation patterns, much research focuses on a two-phase mosaic structure of high- and low-vegetation cover patches, which commonly presents itself in semi-arid ecosystems (Pellerin et al. 2009; Puigdefabregas 2005; Bromley et al. 1997; Cerda 1997; Wilcox et al. 2003). Mechanisms of patch formation and dynamics have also been conducted (Mayor et al. 2008; Liu et al. 2013; Aguiar and Sala 1999; Bautista et al. 2007). However, most of these 
reports and studies focusing on the two-phase vegetation pattern were carried out on degraded land. And nearly all of these studies described this vegetation development process from a homogeneous to a heterogeneous pattern as a degradation process. Few investigations explore this process in a positive succession without disturbance.

Based on abovementioned issues, the major objectives of this study were to study (1) the variations of vegetation diversity and patterns along the abandoned years, (2) the vegetation dynamics mechanisms of abandoned land, and (3) if there was a vegetation successional trajectory on abandoned land? This paper attempts to describe and analyze the dynamics of vegetation diversity and patterns during the farmland abandonment process and presents a quantitative analysis approach based on vegetation and environmental features.

\section{Study area}

The study was performed in the Yangjuangou Catchment $\left(36^{\circ} 42^{\prime} \mathrm{N}, 109^{\circ} 31^{\prime} \mathrm{E}\right)$ in the Loess Plateau, Shaanxi Province, China (Fig. 1). This catchment has a semiarid continental climate and mean annual precipitation of $535 \mathrm{~mm}$, and had a mean air temperature of $10.6^{\circ} \mathrm{C}$ from 1988 to 2007 according to data from the city meteorological station. The elevation of this catchment ranges from 1,050 to $1,298 \mathrm{~m}$ (Liu et al. 2012). The rainfall of the catchment is concentrated between June and September. The composition of Loess in the Yangjuangou catchment is generally more than $50 \%$ silt $(0.002-0.05 \mathrm{~mm})$ and less than $20 \%$ clay $(<0.002 \mathrm{~mm})$, and the porosity is nearly $50 \%$ (Liu et al. 2012). The experiment plots are located in abandoned cropland. Due to sparse population and a grazing ban after these croplands were abandoned, there is little human disturbances on secondary vegetation succession.

\section{Materials and methods}

\section{Experimental design}

For practical reasons, many of the secondary succession studies in abandoned land have been done using a chronosequence approach instead of diachronic studies (Dana and Mota 2006). Abandonment here can be defined as the cessation of plowing and sowing. Before the experiment, personal interviews were held with landowners and managers in order to investigate the age of abandonment. After the interviews, the abandoned land within this catchment mainly contains four abandoned year spans $(4,12,22$, and 50 years) were known. Then, four abandoned lands that consist of these four abandoned year spans were selected for experimental design (Fig. 1). The environmental parameters of these four selected abandoned lands are similar, except for abandoned time (Table 1). From June to October 2012, 15 randomly distributed plots $(1 \times 1 \mathrm{~m})$ were placed on each abandoned land. In each plot, species cover was visually estimated and a cover value was calculated for each species. The location and height of each plant was also recorded for each plot. Twenty-five soil samples were taken at a depth of $20 \mathrm{~cm}$ in five randomly selected plot subsets to determine average soil particle size (PS), bulk density (BD), water content (SWC), total nitrogen (TN), and total carbon (TC). PS was measured using a laser particle sizer (Mastersizer 2000); BD was measured with a soil auger for bulk density, an oven, and a balance; SWC was measured with an oven and a balance; TN and TC were measured using an element analyzer (Vario EL III).

\section{Data analysis}

The degree of succession (DS) was calculated for each plot. According to Numata, the more development in a vegetation community, the higher value the DS will be (Numata 1969; Kitazawa and Ohsawa 2002). Within each plot, the total vegetation cover area (TA) and diversity, using the Shannon diversity index (SHDI), were also calculated. In order to evaluate the vegetation pattern within a plot, the cover area of each plant within its plot was calculated, and the cover boundary of each plant was similarly simulated using a circle. The center of the circle is the plant's location. Meanwhile, the overlaps within each were combined (Fig. 2). In this way, the vegetation patch pattern index, using the Aggregation Index (AI), can be calculated within each plot. According to $\mathrm{He}$ et al., the more aggregation vegetation patches within a class, the higher value the AI will be (He et al. 2000). After these vegetation indexes were calculated, each index in the different abandoned year spans were compared. A least significant difference (LSD) test was used to compare the value of the index (TA, SHDI, and AI) in different abandoned years.

The vegetation patches were here defined as the area within the vegetation boundary, and the bare patches were defined as the area out of the vegetation boundary 

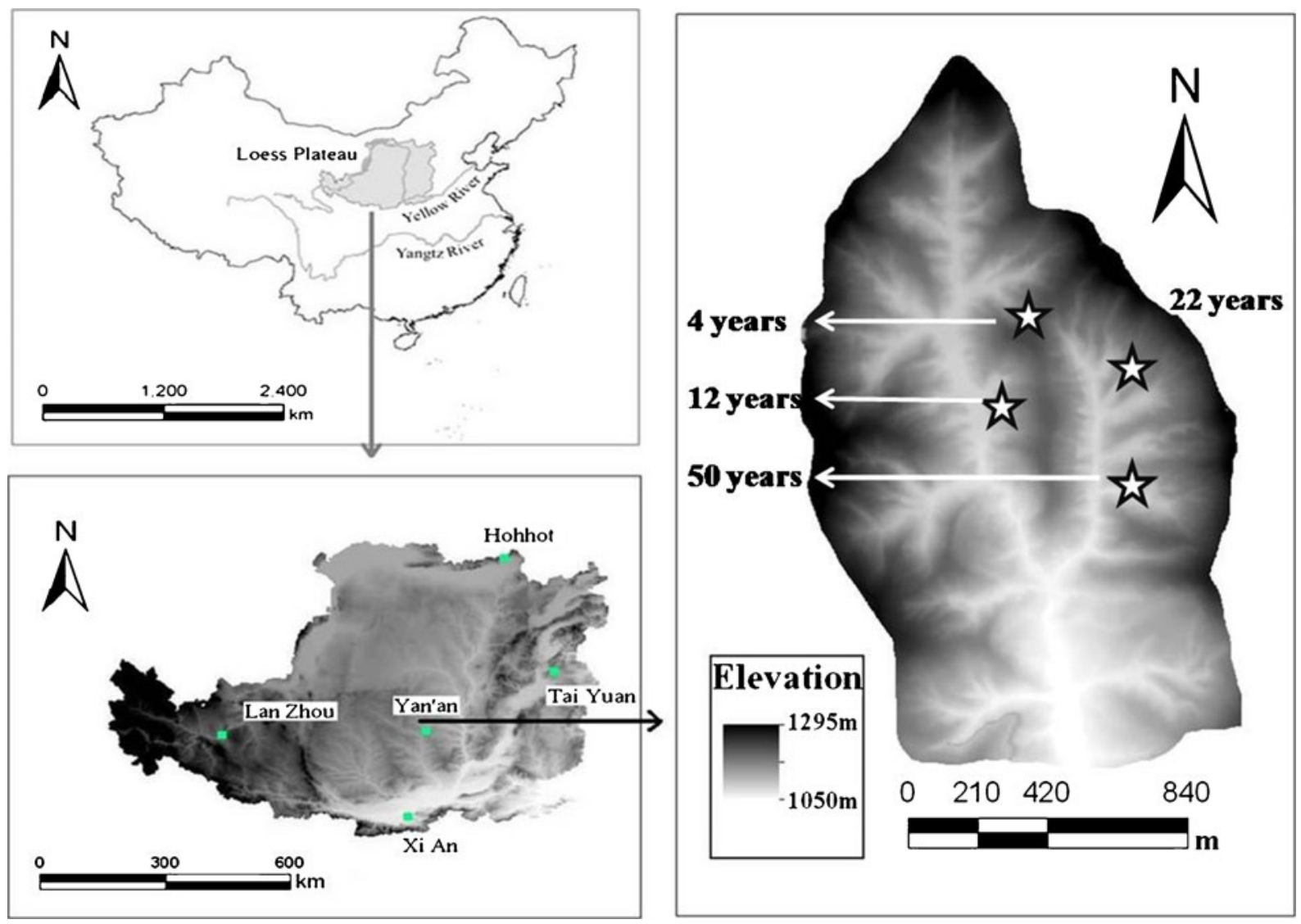

Fig. 1 Locations of experimental lands

in each plot. For each soil sample factor (PS, BD, SWC, TN, and TC), one-way ANOVAs were made to explore whether there is a significant difference between vegetation patches and bare patches in each abandoned year span. The LSD test was also used to compare the value of the index (PS, BD, SWC, TN, and TC) inside or outside the vegetation patch in different abandoned year spans.
Microsoft Excel 2010 was used to analyze and store data. The DS, LSD tests, and ANOVAs were calculated by $\mathrm{R}$ 2.15.2. TA, SHDI, and AI were calculated by ArcGIS 10.0 and Fragstats 4.1. The features and names of every plant species were described according to the Chinese Flora, mentioned in Chinese Vegetation (Wu 1980). ArcGIS 10.0 was used to produce Figs. 1 and 2. Figures 3, 4, and 5 were produced by Origin 8 .

Table 1 The environmental parameters on experimental lands

\begin{tabular}{lllll}
\hline Abandoned time (years) & Slope & Aspect & Elevation (m) & Vegetation community $^{\text {a }}$ \\
\hline 4 & $25^{\circ}$ & WS & 1,195 & Artemisia scoparia + Sonchus brachyotus \\
12 & $24^{\circ}$ & WS & 1,211 & Carex korshinskii + Cleistogenes squarrosa \\
22 & $23^{\circ}$ & WS & 1,194 & Bothriochloa ischcemum + Cleistogenes squarrosa \\
50 & $25^{\circ}$ & WS & 1,200 & Stipa grandis + Silene gallica \\
\hline
\end{tabular}

${ }^{a}$ The nomenclature of the vegetation community is dominant-species nomenclature, followed by Chinese Flora. The vegetation community can be defined by two plants which own the biggest importance value in the vegetation community 
Fig. 2 An example of how to simulate the cover boundary of vegetation patches. The center of the cylinder bottom is the plant location; the height of the cylinder is the height of the plant; and the overlaps within each plant are combined. So, the boundary of the vegetation patch is the outline of the combination

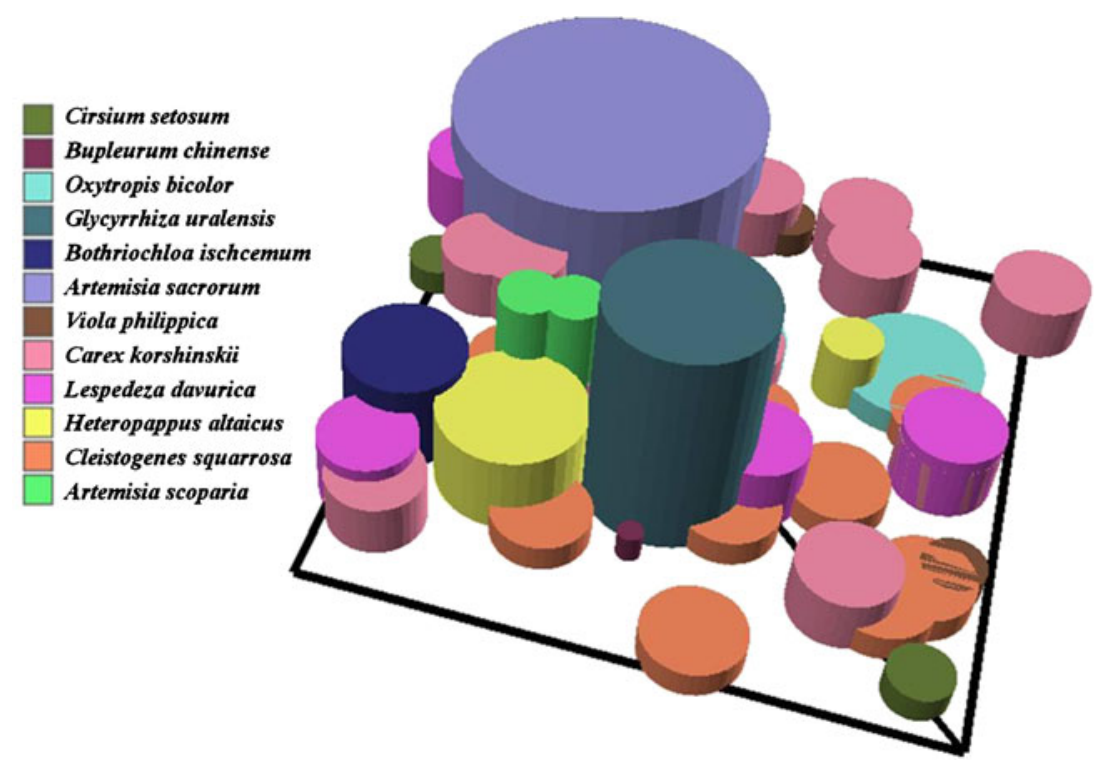

\section{Results}

Vegetation changes during different abandoned year spans

The mean values of DS increase from nearly 100 on 4year abandoned land to 369 on 50-year abandoned land (Fig. 3). This result validated the ages of abandonment

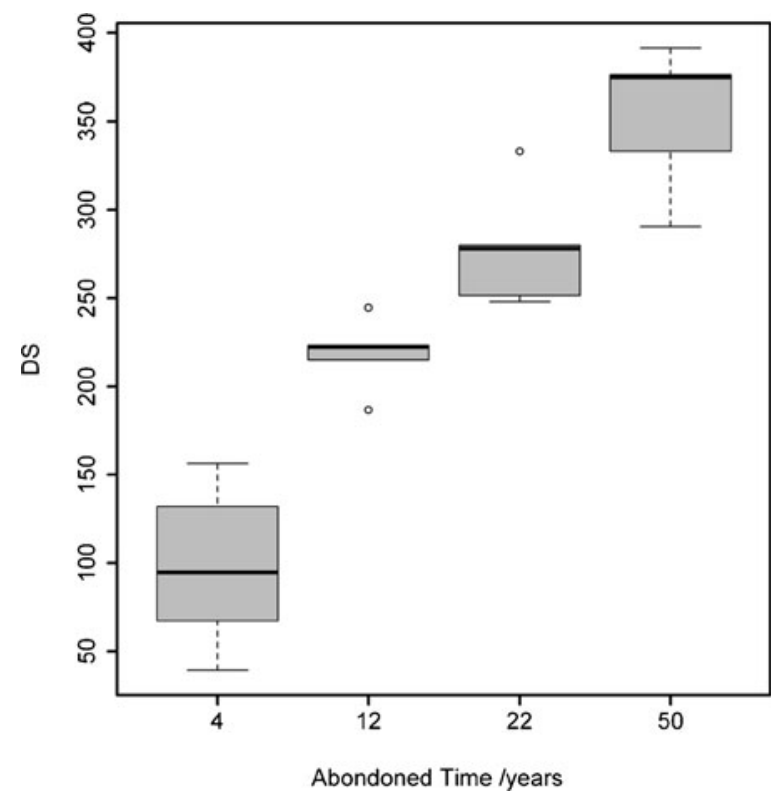

Fig. 3 Degree of succession (DS) on different year spans of abandoned land obtained from the personal interview. The range of TA is from 0.47 to $1 \mathrm{~m}^{2}$, and there is no significant difference about TA on these four abandoned land areas after calculating with LSD tests (Fig. 4). So, vegetation cover has no obvious change with increasing abandoned time in this study. The values of SHDI on 12and 50-year abandoned land range from 2.0 to 2.4. But the values of SHDI on 4- and 22-year abandoned land are mainly lower than 1.8 (Fig. 4). There is a significant difference between these two groups. This means that vegetation diversity goes through a complex change when abandoned time increases. The AI increased from nearly 98.2 to 99.7 with the increasing abandoned time (Fig. 4). Additionally, there is a significant increase between 4- and 12-year abandoned land, and between 12-, 22-, and 50-year abandoned land (Fig. 4). This suggests that vegetation distribution obviously changes from a homogeneous to a heterogeneous pattern with the increase of abandoned time on an experimental field.

Soil properties under different abandoned year spans

Five soil parameters (PS, BD, SWC, TN, and TC) were measured to compare whether there is a significant difference between the inside and outside of the vegetation patches on these four abandoned land areas. It was found that there is no significant SWC difference between inside and outside of the vegetation patches (Table 2). PS was similar in vegetation and bare 

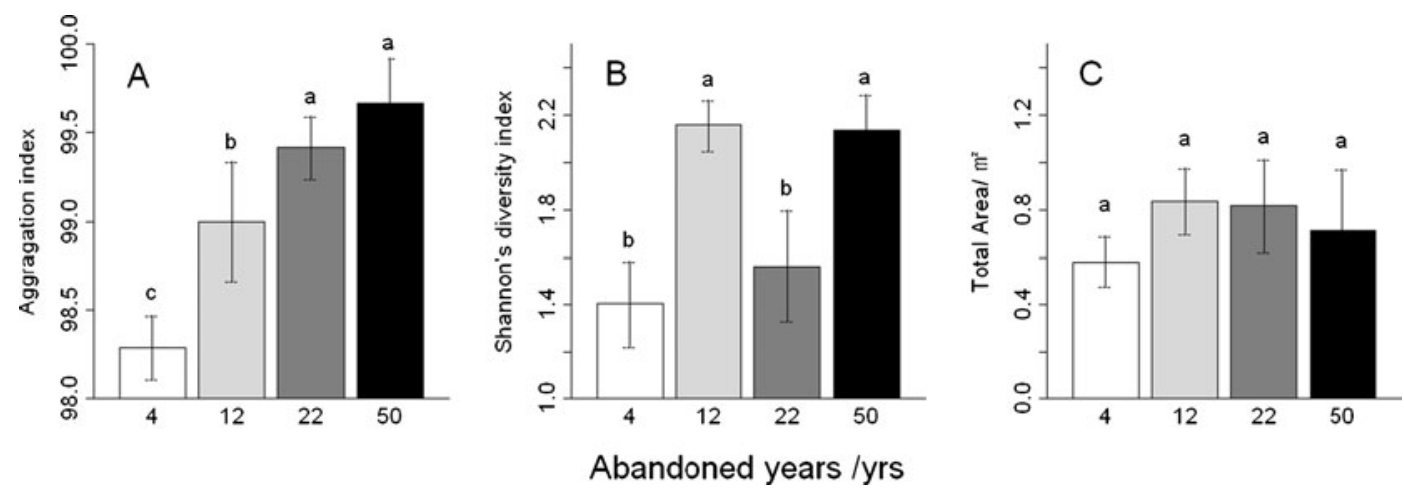

Fig. 4 LSD tests for AI, SHDI, and TA on different year spans of abandoned land

patches on 4- and 12-year abandoned land (Table 2). The values of the PS in the vegetation patch are significantly lower than in the bare patch on 22- $(P<0.01)$ and 50-year $(P<0.05)$ abandoned land (Table 2$)$. The values of the $\mathrm{BD}$ in the vegetation patches are also significantly lower than in the bare patches on 12-
$(P<0.05)$, 22- $(P<0.01)$, and 50-year $(P<0.05)$ abandoned land (Table 2). On 4-year abandoned land, though the value of the $\mathrm{BD}$ in vegetation patches is lower than in the bare patches, there is no significant difference between these two land types $(P=0.461$; Table 2). In terms of TN and TC, there is no significant

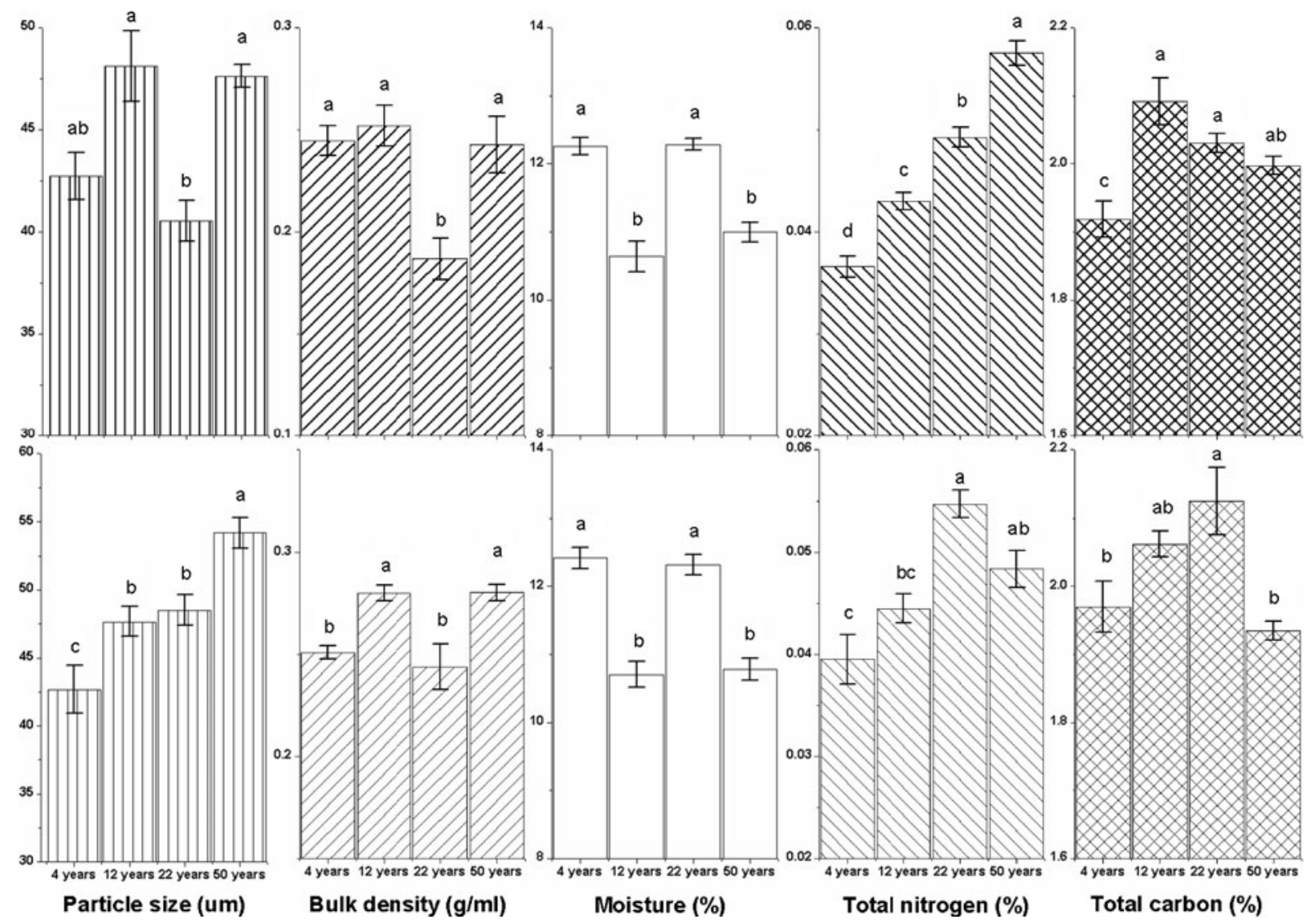

Fig. 5 LSD tests for PS, BD, SWC, TN, and TC within vegetation (top side) and bare patches (bottom side) on different year spans of abandoned land 
Table 2 The results of ANOVA for soil parameters inside and outside of vegetation patches

\begin{tabular}{llllrr}
\hline $\operatorname{Pr}(>F)$ (years) & PS & BD & SWC & TN & TC \\
\hline 4 & 0.982 & -0.461 & -0.445 & -0.299 & -0.302 \\
12 & -0.67 & $-0.0314^{*}$ & -0.822 & 0.819 & -0.447 \\
22 & $-0.00145^{* *}$ & $-0.00549 * *$ & -0.858 & $0.0103^{*}$ & -0.102 \\
50 & $-0.0123^{*}$ & $-0.0299^{*}$ & 0.0345 & $0.00271^{* *}$ & $0.0115^{*}$ \\
\hline
\end{tabular}

Negative values within vegetation patches is lower than within bare patches

$* P=0.05 ; * * P=0.01$, significant codes

difference between the inside and outside of the vegetation patches at the beginning of the abandoned time (4 and 12 years). However, when the land has had enough abandoned time, the values of TN and TC in vegetation patches is significantly higher than in the bare patches $(\mathrm{TN}-22$ years, $P<0.05 ; 50$ years, $P<0.01$; TC -50 years, $P<0.05$; Table 2).

These five soil parameters (PS, BD, SWC, TN, and TC) were also used to compare if there was a significant difference between lands with different abandoned year spans. The TN obviously increases from nearly $0.037 \%$ on 4 -year abandoned land to $0.058 \%$ on 50 -year abandoned land in vegetation patches with the increase of abandoned time (Fig. 5). In bare patches, though the TN increased with the increase of abandoned time, there is no significant difference in the $\mathrm{TN}$ between the 5- and 12-year abandoned land or between on the 22- and 50-year abandoned land (Fig. 5). Compared to the TN, the TC only exhibited a significant difference between the 4-year and other three abandoned land areas within the vegetation patches (Fig. 5). Outside the vegetation patches, the TC on the 4- and 50-year abandoned land (1.9-2.0\%) was significantly lower than on the 22-year abandoned land (nearly $2.1 \%$; Fig. 5 ). Within the bare patches, the PS significantly increases from nearly $42.5 \mu \mathrm{m}$ on the 4-year abandoned land to nearly $54.1 \mu \mathrm{m}$ on the 50 year abandoned land, although there was no significant difference between 12 and 22 years (Fig. 5). Within the vegetation patches, either the PS or the BD had a significantly lower value on the 22-year abandoned land than on the other land (Fig. 5). While, within the bare patches, the BD had a significantly lower value on the 4- and 22-year abandoned land (nearly $0.247 \mathrm{~g} / \mathrm{ml}$ ) than the other land (nearly $0.255 \mathrm{~g} / \mathrm{ml}$; Fig. 5). In terms of SWC, there was a similar status within vegetation patches and bare patches: soil water content had a significantly lower value on the 12- and 50-year abandoned land than on the other land within vegetation or bare patches.

\section{Discussion}

This study confirms that there is not an obvious change in the TA with the increase of abandoned time on land areas. However, the vegetation distribution obviously changes from a homogeneous to a heterogeneous pattern with the increase of abandoned time in an experimental field. This suggests that there is a two-phase mosaic structure of high- (vegetation patches) and low(bare patches) vegetation cover forming on the land. The vegetation patches contain bigger and bigger vegetation cover, but the bare patches contain lower and lower. This research also confirms that vegetation diversity has not experienced a regular change with an abandoned time increase. On a 12-year abandoned land, the vegetation diversity is at the maximum. This suggests that the maximum value of vegetation diversity appears in the middle time span of the second succession of the abandoned land.

Unlike most of the research conducted on degraded land, this research focuses on vegetation pattern changes on abandoned land without any effect on humans or livestock. And, it has been testified to that there is a second succession process on this abandoned land (Fig. 3). Numerous studies conducted on degraded land suggests that vegetation patterns change from homogeneous to heterogeneous due to land degradation (Espigares et al. 2011; Imeson and Prinsen 2004; Ludwig et al. 2005; Moreno-de las Heras et al. 2010). A transition from grassland to shrubland always appears at the end of the degradation. It is said that there is a feedback system between land degradation and vegetation patterns changing from homogeneous to heterogeneous (Muñoz-Robles et al. 2011; Puigdefabregas 
2005). On the contrary, there is a convolution between vegetation succession and vegetation changing from homogeneous to heterogeneous. Vegetation diversity is a research hotspot in ecology. There is a great deal of research focusing on the changing trend of vegetation diversity during succession processes (Firbank et al. 2003a; Randriamalala et al. 2012). As anyone might suggest, there are three changing trends of vegetation diversity during succession processes: increasing, decreasing, and no change. On this experiment field, vegetation diversity followed the third trend. In terms of vegetation cover, there was not an obvious change with the increase of abandoned time on the land.

Though there is little research on vegetation patterns on abandoned land with positive succession, some research on vegetation diversity and cover can be found. For example, Jacquemyn et al. has investigated the role of abandonment in determining species composition and diversity in a calcareous grassland in Belgium. In contrast with the findings of this paper, Jacquemyn et al. concluded that grassland abandonment can lead to a decline of vegetation diversity (Jacquemyn et al. 2011). After researching a second succession, Bonet reached the conclusion similar to that of this paper: plant richness and cover show significant differences between old-field age groups (Bonet 2004). Dana and Mota investigated successional plant and soil dynamics on abandoned quarries, also using the chronosequences approach. They got the results that there is an increase in complexity of communities, an improvement in edaphic conditions, and a stronger positive correlation between the nutritional level and plant communities with an increase in abandoned time (Dana and Mota 2006). Peco et al. studied the changes in floristic composition, species richness, and heterogeneity on abandoned grazing grasslands, and they concluded that species numbers in abandoned zones were not significantly different from grazed zones and floristic heterogeneity increased with abandonment (Peco et al. 2006).

In this study, it was found that each soil parameter (PS, BD, SWC, TN, and TC) is similar for both the inside of and outside of vegetation patches on 4-year abandoned land. And both the vegetation aggregation degree and vegetation diversity are lowest in all abandoned land. So, it is suggested that, in this succession stage, vegetation has a homogeneous distribution, and the two-phase mosaic structure of high- and lowvegetation cover patches does not form maturely.
When the land has been abandoned for 12 years due to vegetation succession, the vegetation community has more richness than on the 4-year abandoned land. Total soil nitrogen and carbon increase over the land, so there is more nutrition to be used for vegetation in the 12-year abandoned time than in the 4-year abandoned time. Under these conditions, vegetation diversity increases. With this successional process, soil erosion from water or wind can also have an influence on the land. Silt particles may be transported from bare patches in this way. It is known that silt particles in the soil contain more nutrition than coarse particles. Therefore, it is possible that the conditions in the bare patches are not better than in the vegetation patches in the 12-year abandoned time. This suggestion has been verified by testing the soil bulk density. Due to similar soil type, a bigger bulk density value means a bigger porosity in the soil. The results of this study show that not only is the value of $\mathrm{BD}$ in this stage bigger than in the 4-year abandoned time, but also the value of $\mathrm{BD}$ within the vegetation patches is bigger than it is within the bare patches. Thus, it follows that the soil within the vegetation patches has a larger porosity than the soil within bare patches, and the soil within bare patches in this abandoned time becomes more compact than the soil in the 4-year abandoned time. It is clear that the conditions within the vegetation patches are better than within the bare patches. In this way, we can see that the two-phase mosaic structure of high- and low-vegetation cover patches forms in this stage.

On land, where the abandoned time has lasted for 22 years, silt, BD, and TN exhibit a significant difference between the inside and outside areas of vegetation. This phenomenon in the 22-year abandoned land is more obvious than in 12-year abandoned land. Either soil physical and nutritional properties are better for vegetation within the vegetation patches than within the bare patches. So, the vegetation patches in this 22 -year abandoned stage will be stronger than in 12-year abandoned land, and the two-phase mosaic structure pattern becomes more and more obvious. However, vegetation diversity decreases with a TN increase. It is suggested that though the $\mathrm{TN}$ increased in this stage, the heterogeneous pattern became increasingly mature. More and more plants tended to aggregate in the vegetation patches. So, it is possible that strong interspecies competition emerged in this stage, and the vegetation diversity decreased.

On the 50-year abandoned land, the two-phase mosaic pattern of vegetation and bare patches has formed. 
Either soil physical (PS and BD) or nutritional (TN and TC) properties are better for vegetation within the vegetation patches than within the bare patches. Vegetation distribution in a heterogeneous pattern was at its mature stage. There was a minimum niche overlap between different species, and there was maximize resource utilization within the vegetation patches. So, though there was strong competition between species, vegetation diversity increased with the increase of $\mathrm{TN}$.

\section{Conclusion}

Based on the research of four different types of abandoned land, it was found that the vegetation distribution development changed from homogeneous (on 4year abandoned land) to heterogeneous (on 50-year abandoned land) with a postsuccession. Meanwhile, with the forming of two-phase mosaic structure of high- and low-vegetation cover patch, there was a significant difference in soil physical and nutritional properties inside and outside of vegetation patches. Vegetation patches can supply better conditions for vegetation than bare patches as the abandoned time increased. Due to the effect of the environment and interspecies competition on vegetation, vegetation diversity changed without a regular trend. It was found that in the 12-year abandoned land, vegetation diversity achieved its maximum. After this stage, this value decreased in the 22-year abandoned land because of competition and rose again in the 50-year abandoned land due to sound resource utilization. In this study, only four types of abandoned land were investigated. So, although there is a main successional vegetation trajectory on abandoned land, some details may have been ignored. These details need attention in future work on additional year spans of abandoned land.

Acknowledgments The research was supported by National Natural Science Foundation of China (No. 41230745) and External Cooperation Program of the Chinese Academy of Sciences (No. GJHZ1215).

\section{References}

Aguiar, M. R., \& Sala, O. E. (1999). Patch structure, dynamics and implications for the functioning of arid ecosystems. Tree, 14, 273-277.
Bautista, S., Mayor, Á. G., Bourakhouadar, J., \& Bellot, J. (2007). Plant spatial pattern predicts hillslope runoff and erosion in a semiarid mediterranean landscape. Ecosystems, 10(6), 987-998.

Boer, M., \& Puigdefabregas, J. (2005). Effects of spatially structured vegetation patterns on hillslope erosion in a semiarid Mediterranean environment: a simulation study. Earth Surface Processes and Landforms, 30(2), 149-167.

Bonet, A. (2004). Secondary succession of semi-arid Mediterranean old-fields in south-eastern Spain: insights for conservation and restoration of degraded lands. J Arid Environ, 56(2), 213-233.

Bromley, J., Brouwer, J., Barker, A. P., Gazea, S. R., \& Valentind, C. (1997). The role of surface water redistribution in an area of patterned vegetation in a semi-arid environment, southwest Niger. Journal of Hydrology, 198, 1-29.

Buhk, C., Retzer, V., Beierkuhnlein, C., \& Jentsch, A. (2007). Predicting plant species richness and vegetation patterns in cultural landscapes using disturbance parameters. Agr Ecosyst Environ, 122(4), 446-452.

Cerda, A. (1997). The effect of patchy distribution of Stipa tenacissima L. on runoff and erosion. J Arid Environ, 36, 37-51.

Critchley, C. N. R., \& Fowbert, J. A. (2000). Development of vegetation on set-aside land for up to nine years from a national perspective. Agriculture, Ecosystems and Environment, 79, 159-174.

Dana, E. D., \& Mota, J. F. (2006). Vegetation and soil recovery on gypsum outcrops in semi-arid Spain. J Arid Environ, 65(3), 444-459.

Donath, T. W., Bissels, S., Hölzel, N., \& Otte, A. (2007). Large scale application of diaspore transfer with plant material in restoration practice - impact of seed and microsite limitation. Biol Conserv, 138(1-2), 224-234.

Ellum, D. S., Ashton, M. S., \& Siccama, T. G. (2010). Spatial pattern in herb diversity and abundance of second growth mixed deciduous-evergreen forest of southern New England, USA. For Ecol Manage, 259(8), 1416-1426.

Espigares, T., Las Heras Moreno-de, M., \& Nicolau, J. M. (2011). Performance of vegetation in reclaimed slopes affected by soil erosion. Restoration Ecology, 19(1), 35-44.

Firbank, L. G., Barr, C. J., Bunce, R. G. H., Furse, M. T., HainesYoung, R., Hornung, M., et al. (2003a). Assessing stock and change in land cover and biodiversity in GB: an introduction to Countryside Survey 2000. J Environ Manage, 67(3), 207-218.

Firbank, L. G., Smart, S. M., Crabb, J., Critchley, C. N. R., Fowbert, J. W., Fuller, R. J., et al. (2003b). Agronomic and ecological costs and benefits of set-aside in England. Agr Ecosyst Environ, 95(1), 73-85.

Haines-Young, R., Barr, C. J., Firbank, L. G., Furse, M., Howard, D. C., McGowan, G., et al. (2003). Changing landscapes, habitats and vegetation diversity across Great Britain. J Environ Manage, 67(3), 267-281.

He, H. S., Dezonia, B. E., \& Mladenoff, D. J. (2000). An aggregation index (AI) to quantify spatial patterns of landscapes. Landsc Ecol, 15, 591-601.

Imeson, A. C., \& Prinsen, H. A. M. (2004). Vegetation patterns as biological indicators for identifying runoff and sediment source and sink areas for semi-arid landscapes in Spain. $\mathrm{Agr}$ Ecosyst Environ, 104(2), 333-342. 
Jacquemyn, H., Mechelen, C. V., Brys, R., \& Honnay, O. (2011). Management effects on the vegetation and soil seed bank of calcareous grasslands: an 11-year experiment. Biol Conserv, 144(1), 416-422.

Kitazawa, T., \& Ohsawa, M. (2002). Patterns of species diversity in rural herbaceous communities under different management regimes, Chiba, Central Japan. Biol Conserv, 104, 239-249.

Liu, Y., Fu, B., Lü, Y., Wang, Z., \& Gao, G. (2012). Hydrological responses and soil erosion potential of abandoned cropland in the Loess Plateau, China. Geophys J Roy Astron Soc, 138(1), 404-414.

Liu, H., Zhao, W., \& He, Z. (2013). Self-organized vegetation patterning effects on surface soil hydraulic conductivity: a case study in the Qilian Mountains, China. Geoderma, 192, 362-367.

Ludwig, J. A., Wilcox, B. P., Breshears, D. D., Tongway, D. J., \& Imeson, A. C. (2005). Vegetation patches and runofferosion as interacting ecohydrological processes in semiarid landscapes. Ecology, 86(2), 288-297.

Martin, C., Pohl, M., Alewell, C., Körner, C., \& Rixen, C. (2010). Interrill erosion at disturbed alpine sites: effects of plant functional diversity and vegetation cover. Basic and Applied Ecology, 11(7), 619-626.

Mayor, Á. G., Bautista, S., Small, E. E., Dixon, M., \& Bellot, J. (2008). Measurement of the connectivity of runoff source areas as determined by vegetation pattern and topography: a tool for assessing potential water and soil losses in drylands. Water Resour Res, 44(10), W10423.

las Heras Moreno-de, M., Nicolau, J. M., Merino-Martín, L., \& Wilcox, B. P. (2010). Plot-scale effects on runoff and erosion along a slope degradation gradient. Water Resour Res, 46(4), W04503.

Muñoz-Robles, C., Reid, N., Tighe, M., Briggs, S. V., \& Wilson, B. (2011). Soil hydrological and erosional responses in patches and inter-patches in vegetation states in semi-arid Australia. Geoderma, 160(3-4), 524-534.

Numata, M. (1969). Progressive and retrogressive gradient of grassland vegetation measured by degree of succession. Vegetatio, 19, 96-127.
Pearman, P. B., \& Weber, D. (2007). Common species determine richness patterns in biodiversity indicator taxa. Biol Conserv, 138(1-2), 109-119.

Peco, B., Sánchez, A. M., \& Azcárate, F. M. (2006). Abandonment in grazing systems: consequences for vegetation and soil. Agr Ecosyst Environ, 113(1-4), 284-294.

Pellerin, S., Lagneau, L.-A., Lavoie, M., \& Larocque, M. (2009). Environmental factors explaining the vegetation patterns in a temperate peatland. CR Biol, 332(8), 720-731.

Puigdefabregas, J. (2005). The role of vegetation patterns in structuring runoff and sediment fluxes in drylands. Earth Surface Processes and Landforms, 30(2), 133-147.

Randriamalala, J. R., Hervé, D., Randriamboavonjy, J.-C., \& Carrière, S. M. (2012). Effects of tillage regime, cropping duration and fallow age on diversity and structure of secondary vegetation in Madagascar. Agr Ecosyst Environ, 155, 182-193.

Rickert, C., Fichtner, A., van Klink, R., \& Bakker, J. P. (2012). $\alpha$ - and $\beta$-diversity in moth communities in salt marshes is driven by grazing management. Biol Conserv, 146(1), 2431.

Saco, P. M., Willgoose, G. R., \& Hancock, G. R. (2007). Ecogeomorphology of banded vegetation patterns in arid and semi-arid regions. Hydrology and Earth System Sciences, 11, 1717-1730.

Walker, K. J., Stevens, P. A., Stevens, D. P., Mountford, J. O., Manchester, S. J., \& Pywell, R. F. (2004). The restoration and re-creation of species-rich lowland grassland on land formerly managed for intensive agriculture in the UK. Biol Conserv, 119(1), 1-18.

Wilcox, B. P., Breshears, D. D., \& Turin, H. J. (2003). Hydraulic conductivity in a pinon-juniper woodland: influence of vegetation. Soil Science Society of America Journal, 67, 12431249.

Wu, Z. Y. (1980). China vegetation. Beijing: Science Press.

Yetemen, O., Istanbulluoglu, E., \& Vivoni, E. R. (2010). The implications of geology, soils, and vegetation on landscape morphology: Inferences from semi-arid basins with complex vegetation patterns in Central New Mexico, USA. Geophys J Roy Astron Soc, 116(3-4), 246-263. 